\title{
El niño como sujeto ético
}

Luciano Lutereau ${ }^{1}$

\section{Resumen}

Hoy en día, en nuestra sociedad de consumo postcapitalista, se valora muy bien el tener una opinión. Sobre todo tenemos un parecer, todas las semanas, si no todos los días, nos expedimos sobre algún asunto. Creamos grietas, nos ponemos de un lado o del otro, nos olvidamos de que a veces discutimos a muerte con personas que quizá comparten con nosotros mucho más de los pensamos. Por eso en este artículo quisiera reflexionar sobre el origen psíquico de la empatía y, en particular, sobre la génesis del perdón en la infancia.

Palabras clave: perdón, empatía, psico-génesis, infancia, psicoanálisis.

\section{Abstract}

Today, in our post-capitalist consumer society, having an opinion is highly valued. We have an opinion about

1 Universidad de Buenos Aires, https://www.lucianolutereau.com/ 
everything, every week, if not every day, we position ourselves on some matter. We create cracks, we stand on one side or the other, we forget that sometimes we argue to the death with people who perhaps share much more with us than we think. That is why in this article I would like to reflect on the psychic origin of empathy and, in particular, on the genesis of forgiveness in childhood.

Keywords: forgiveness, empathy, psycho-genesis, childhood, psychoanalysis.

Hoy en día, en nuestra sociedad de consumo post-capitalista, se valora muy bien el tener una opinión. Sobre todo tenemos un parecer, todas las semanas, si no todos los días, nos expedimos sobre algún asunto. Creamos grietas, nos ponemos de un lado o del otro, nos olvidamos de que a veces discutimos a muerte con personas que quizá comparten con nosotros mucho más de los pensamos. Por eso en este artículo quisiera reflexionar sobre el origen psíquico de la empatía y, en particular, sobre la génesis del perdón en la infancia.

\section{Las raíces agresivas del juego}


Hace un tiempo un colega me comentó una situación de su práctica. Recibió en la consulta a una niña que no se disponía al tratamiento. Ella rechazaba sus invitaciones lúdicas, le respondía que se aburría; pero después de jugar un tiempo, la pequeña estaba alegre. ¿Por qué necesitaba alejarse para, luego, entrar en la sesión? Qué diferente a esas niñas que llegan al consultorio y se ponen a dibujar, que incluso al concluir el encuentro nos regalan los dibujos y hasta nos piden que los exhibamos... para que otros niños los vean. Un modo de mostrarse como "preferidas".

En el caso de la niña en cuestión, la separación reciente de sus padres la tenía un poco inquieta respecto de la presencia de aquellos. De ahí que estuviera tan pendiente del otro, que le enrostrase su malestar, como un modo de no perderlo vista, tal vez de poner a prueba su permanencia. El aspecto interesante en la supervisión del caso de mi colega estuvo en delimitar que, antes que un fracaso en el inicio del tratamiento, esa era la vía de iniciar la consulta. La niña se relacionaba desde un vínculo hostil, pero ¿qué podría hacernos creer que la relación más dócil y amable es preferible?

En efecto, muchos niños hacen del aburrimiento un modo prístino de vínculo con los adultos. Es un modo de relación agresiva, ya que el célebre "me aburro" tiene como fin impotentizar al adulto. De antemano el niño sabe que no se le responderá: "Bueno, es un problema tuyo". No hoy, cuando en el siglo XXI los pa- 
dres son tan sensibles a la demanda de los hijos y no quieren frustrarlos. Asimismo, la otra cara de esa actitud es que les cueste mucho reconocer los aspectos agresivos.

Por ejemplo, nos encanta la idea de que los niños jueguen, pero no nos gusta que el juego implique pulsiones agresivas. La relación entre juego y agresión resulta casi insoportable, no solo para adultos, sino también para profesionales - sobre todo para los que no pueden renunciar a una idea beatífica del niño- pero ¿podemos negar que, por ejemplo, si un niño hace una torre, para otro puede haber nada más divertido que ir a rompérsela? A veces ese entretenimiento puede ser hasta compulsivo. Según cómo se intervenga es que se tendrá una idea de qué noción de juego tiene quien habla: ¿quién puede negar un placer de destruir las cosas del otro? Peor sería destruir al otro, en ese sentido el juego ya es una instancia de elaboración; peor sería si en vez de romper su torre, va y le pega en la cabeza. Ahí ya no hay juego; pero cuando patea su torre se divierte. ¿Está mal? ¿Se podría juzgar moralmente? ¿Por qué no reconocer que el juego también implica un lazo agresivo? De nada serviría decirle que no lo haga, mucho menos creer que si juega a eso es porque no puede jugar a otra cosa "mejor". Con el tiempo, ese destino agresivo es la fuente, por ejemplo, de los juegos de competencia y rivalidad. Cualquiera sabe que ganar solo en un solitario no está tan bueno como ganarle a otro en el truco, los dados, etc. Cuesta tanto 
asumir la deriva agresiva del juego, porque ahí está la raíz hostil que luego también se aplica al erotismo.

Hay personas que se excitan provocándose, que se erotizan con un chiste malo o una burla hacia el otro; en ciertas parejas la molestia insidiosa llega a ser parte de un idioma íntimo del amor. Podríamos decir que esto tampoco es amor, pero no va a dejar de ocurrir porque lo digamos. El punto me parece que es otro, más bien notar la diferencia entre un uso simbólico de la hostilidad y una acción hiriente. Esa diferencia se hace con un trabajo de esclarecimiento de los diques psíquicos, sobre todo la vergüenza. Como toda diferenciación en psicoanálisis, tiene que hacerse desde posiciones subjetivas y no como clasificación de conductas.

\section{El niño, sujeto ético}

Todavía no terminamos de sacar las conclusiones que implica haber atravesado los complejos psíquicos infantiles de destete y control de esfínteres. Creemos que se trata del control de funciones fisiológicas, pero de su eficacia depende un paso adelante en la subjetivación que, si hoy podemos pensar, es por su relativa ausencia.

El destete no se relaciona con el momento de dejar la teta, sino con desprenderse del goce de la succión. Hay niños que dejaron de mamar y no están destetados, también los que continúan con lactancia de pecho y lo están. Asimismo, en el destete el niño no se 
separa de la madre, sino de una parte de sí mismo; por último, no es la madre la que desteta al niño, sino éste quien realiza una operación psíquica.

En un primer momento, un niño que se amamanta es una especie de tubo por el que ingresa un flujo continuo: la leche. Un precedente del destete está en la regurgitación, que eventualmente puede acompañarse de vómitos. Así es que el niño descubre el goce de tragar, cuyo paso siguiente está en el placer de morder. Para este entonces, el niño ya no se alimenta de la teta solamente, ya no chupa, sino que también juega y, como dicen algunas madres, puede ser que esté un rato largo "franeleando" con la teta. En ese punto ya es posible que una madre prefiera que juegue mejor con un juguete.

El destete lleva al juego, es también lo que permite ver el nacimiento erótico de la experiencia lúdica. Asimismo, un niño destetado es el que proyecta el goce de succión en la primera gran fantasía de la infancia: la de devoración. A un niño destetado se lo reconoce porque inmediatamente empieza a tener miedo, temores nocturnos, a quedarse solo, todos temores normales, que implican que haberse desprendido de una parte del propio cuerpo es equivalente a instituir la primera gran diferencia psíquica: entre afuera y adentro. Afuera hay un monstruo, ladrones, etc., pero sea lo que sea, se trata siempre de que hay otro lugar y que la pulsión que inviste ese espacio es oral: me pueden comer. No por nada es que en esta época es que aparece el interés 
por los cuentos infantiles que giran en torno a esta cuestión: Caperucita, Hansel y Gretel, etc.

Ahora bien, la otra cara de la fantasía de devoración proyectada en el afuera, es lo que en el niño se siente como culpa. Es este un paso curioso: haber rechazado una parte de su cuerpo, es vivido como haber castrado a la madre, ¿por qué si no se lo habrían de comer? Esto puede parecer algo abstracto, pero se refleja en múltiples conductas de la infancia, sobre todo la de esos niños que buscan ser retados, aquellos que hacen enojar a los padres para que muestren su costado más monstruoso, porque — por ejemplo— si le dicen al niño que no toque un objeto, ¿qué hace el niño? Va y lo toca. Es claro que en este punto no se trata de un déficit cognitivo, sino de una pulsión de castigo en el niño que lo lleva a buscar alivio en ser reprendido. Aunque llore, porque ¿no es este también el momento en que los niños lloran y los padres dicen "no sé qué le pasa"?

A un niño no se lo castiga para hacerlo sentir culpable, sino todo lo contrario. Si es preciso reprenderlo, que sea para liberarlo de la culpa. Mejor decirle: "Este vaso lo voy a sacar de la mesa para que no se caiga". Ningún sentido tendría anticiparle, en este tipo de momento: "No toques el vaso que se puede caer" y luego: "Te dije que no toques el vaso que se podía caer". El niño lo vivirá, de acuerdo con el atravesamiento del destete, como que él es rechazable, se confirmará así no que hizo algo de lo que tiene la culpa, sino que es cul- 
pable. Esta diferencia es sutil, pero importante: en la oralidad, la lógica es de todo o nada; para apreciar mejor esta distinción podría decir: no es lo mismo haber cometido un acto delictivo que ser un delincuente. Para el niño se trata más bien de esto último, es con su ser entero que responde al castigo, por eso la fantasía devoración no incumbe a que se le comerá una parte del cuerpo, ¡sino el cuerpo entero! La eficacia de esta fantasía no se comprueba solo en el interés de los niños por los cuentos, sino en el modo en que viven la culpa y el modo en que interpretan los castigos.

Entonces, ¿cómo es que el niño pasa a la lógica de la parte/todo? Con el complejo de control de esfínteres, que no se relaciona con el hábito de dejar de hacer caca en pañales. En todo caso, lo que este hábito representa es la capacidad de darle a otro una capacidad de renuncia y, por lo tanto, convertirlo en una persona con autoridad. Es claro que un niño puede dejar de hacerse caca encima y no por eso haber renunciado a nada. Asimismo, darle al otro un lugar de autoridad es poder aceptar un juicio que provenga de su parte e identificar que en mí puede haber algo reprobable ("Juancito, te estás moviendo mucho, ¿por qué no vas al baño?"). No es un aspecto menor, ies toda una adquisición! Porque si con el destete se habilitaba la distinción adentro/afuera, con el control de esfínteres se consigue la diferencia entre yo y no yo; o, mejor dicho, el yo deja de ser una instancia pura o totalizante y tiene partes, algunas mejores que otras, en fin, así es como 
un niño puede admitir que hizo algo malo sin por eso creer que él es reprobable.

Nuevamente esto puede parecer abstracto, pero es algo cotidiano. Acaso, ¿no hay personas que no pueden recibir el menor señalamiento sin ofenderse? ¿No ocurre esto también con los padres que traen a los niños a la consulta, cuando por ejemplo si no pueden venir dicen: "Me vas matar, no podemos ir hoy" (fantasía de devoración), si no agregan: "Igual te vamos a pagar la sesión" (respuesta anal)? Esto es lo maravilloso del psicoanálisis, que aquellas piezas de la teoría que parecen francamente delirantes, son la clave de inteligibilidad de nuestra vida cotidiana.

De este modo, ¿cuál es la adquisición del complejo de control de esfínteres? Es la herida narcisista. Quien atravesó este complejo, puede dejar a un lado su narcisismo en el lazo con el otro. No es un rendimiento menor. Es cierto que todavía es necesario que se sume el complejo de castración para que un niño sea un sujeto moral en el sentido más estricto. Porque ¿qué ocurre en este momento, por ejemplo, si un niño baja una escalera con otro niño y lo empuja? Si se lo preguntamos, dirá que fue él y si le decimos que por eso está castigado, dirá que está bien; pero si el castigo es dejar de comer postre es muy posible que nos pida igualmente el postre, dado que aún para el niño no se tejió la relación entre un acto y sus consecuencias.

Esto es lo que en psicoanálisis llamamos "complejo de castración", que no tiene que ver con que a al- 
guien lo amenacen con que le van a cortar algo, sino con asumir que entre un acto y su consecuencia hay efectos que son imprevisibles, que el pensamiento no reduce esa brecha, que a veces ni siquiera sirve decir "Nunca me lo imaginé", o tal vez "Yo no quería". El sujeto de la intención está todavía fijado en la analidad, ¿qué es la "intencionalidad" sino eso que está dentro de uno y sobre lo que cada quien cree que decide? Es pura mierda. Si volvemos al ejemplo anterior, si a un niño que atravesó el complejo de castración le preguntamos si empujó al otro niño, nos dirá: "Yo apenas lo toqué, puse las manos así, entonces...". Este es el momento en que las cosas empiezan a "caerse solas". Con la castración es que los niños ni siquiera se toman el trabajo de mentir, ahora ise empiezan a hacer los tontos! ¡Como los adultos!

\section{Empatía y perdón}

Después de todo este rodeo creo que puedo desarrollar, para concluir, lo que más me interesa explicar. Me importa situar una coordenada específica: ¿qué ocurre cuando a un niño que aún no atravesó el complejo de control de esfínteres le planteamos que hizo algo mal (por ejemplo, empujar a su amigo)? Como dije, dirá que él fue; tal vez que no lo hizo a propósito, con el tiempo incluso puede querer engañarnos, pero más notorio será que fue él. Le diremos: "Pedile perdón a tu amigo" y, entonces, veremos una escena tan particular: se nega- 
rá o, tal vez, se acerque y diga "perdón" en voz baja o, tanto peor (y más gracioso) quizá se lo grite y diga "Bueno, ya se lo dije, ibasta!". Porque para pedir perdón es preciso haber subjetivado la herida narcisista. La entrada en este complejo va de la mano de darle al otro la autoridad para juzgarnos, pero este otro no es un par; la herida narcisista, en cambio, es algo que se juega con un semejante e implica poder destituir el orgullo para situar que algo que hicimos pudo haberlo lastimado. Aquí ya estamos en la lógica de la castración: "Aunque no quise, te lastimé, tengo que pedirte perdón".

Esta distinción es fundamental porque permite apreciar la diferencia crucial entre la compasión y la empatía. Por ejemplo, no es raro escuchar a personas que cuentan cómo se conmueven con pobres en la caIle. Los afecta profundamente, pero esta compasión no depende muchas veces de otra cosa que de una identificación narcisista; lo que siento no es más que una proyección de lo que yo (creo que) sentiría si estuviera en la misma situación y, eventualmente, la limosna no funciona de otro modo que como una manera más o menos supersticiosa de querer evitar que me pase. Este es el resorte último de la lástima. La compasión siempre es, en última instancia, autocompasiva.

Algo muy distinto es lo que ocurre con la empatía, porque en esta última no se trata de una proyección de uno mismo; mucho menos de lástima, sino que es preciso haber atravesado la castración para medir el efec- 
to de los actos en la vida de otro. Tomemos el mismo ejemplo: ante un pobre puedo ser piadoso (que es un modo de ser empático) en la medida en que reconozco lo injusto del mundo con su situación. Aquí se puede dar una mano desde otro lugar que no sea la lástima. Este es el origen de la caridad, que si no renuncia al egoísmo y al temor no es tal. Por lo tanto, para concluir, quisiera destacar cómo las virtudes éticas fundamentales: empatía, piedad, caridad, tienen su origen en el complejo de castración y éste es el que le da sentido al perdón como lazo comunitario. Todas estas cosas se aprenden en la infancia, o no se aprenden nunca. 


\section{(9) $(\Theta \odot \odot$}

\section{Esta obra está bajo una \\ Licencia Creative Commons Atribución-NoComercial- Compartirlgual 4.0 Internacional}

Usted es libre de compartir o adaptar el material en cualquier medio o formato bajo

las condiciones siguientes: (a) debe reconocer adecuadamente la autoría, proporcionar un enlace a la licencia e indicar si se han realizado cambios; (b) no puede utilizar el material para una finalidad comercial y (c) si remezcla, transforma o crea a partir del material, deberá difundir sus contribuciones bajo la misma licencia que el original.

Resumen de la licencia

https://creativecommons.org/licenses/by-nc-sa/4.0/deed.es_ES Texto completo de la licencia https://creativecommons.org/licenses/by-ncsa/4.0/legalcode 